\title{
ON A RESUlT CONCERNING A PROPERTY OF CLOSED MANIFOLDS
}

\author{
DORIN ANDRICA
}

Abstract. The main result is given in Theorem 2 and it shows that the inequality $\gamma(\widetilde{M}) \leqslant$ $k \gamma(M)-4(k-1)$ contained in Theorem 1 holds with equality for any closed smooth surface $M^{2}$ (orientable or not), where $\pi: \widetilde{M} \rightarrow M$ is a $k$-covering of $M$ and $\gamma(M)$ is the Morse-Smale characteristic of $M$.

Mathematics subject classification (2000): 57R70, 58E05, 26D99.

Key words and phrases: Morse-Smale characteristic, manifold, $k$-covering, closed smooth surface.

\section{REFERENCES}

[1] ANDRICA, D., Some remarks concerning the Morse-Smale characteristic of a compact manifold, Revue Anal. Numerique Téorie Approx., Tome 21, No.1, (1992) 9-13.

[2] ANDRICA, D., The Morse-Smale characteristic of a simply-connected compact manifold, Revue Anal. Numerique Téorie Approx., Tome 22, No.2, (1993) 121-124.

[3] ANDRICA, D., Note on a result of G.M. Rassias, Proceedings of the $23^{\text {rd }}$ Conference on Geometry and Topology (D. Andrica, P. Enghiş, Eds.), Cluj-Napoca, 1994, 1-5.

[4] ANDRICA, D., Functions with a minimal number of critical points, Proceedings of the International Workshop on Differential Geometry and Topology and its Applications, Bucharest, July 25-30 (1993), Polytechnica University Bucharest, 1996, 35-43.

[5] ANDRICA, D., Functions with minimal critical set: new results and open problems, Mathematical Analysis and Applications, Th. M. Rassias, Ed., Hadronic Press, Florida, 1999, 1-10.

[6] BotT, R., The stable homotopy type of the classical groups, Ann. of Math. 70(1959), 313-337.

[7] CECIL, T. E., RYAN, P. J., Tight and taut immersions of manifolds, Research Notes in Math., Vol.107, Pitman, 1985.

[8] HAJduK, B., Comparing handle decomposition of homotopy equivalent manifolds, Fund. math. 95(1977), No.1, 3-13.

[9] KuIPER, N. H., On surfaces in Euclidean three space, Bull. Soc. Math. Belg. 12(1960), 5-12.

[10] KUIPER, N. H., Tight Embeddings and Maps. Submanifold of Geometrical Class Three in $E^{N}$, The Chern Symposium 1979 (Proc. Internat. Sympos., Berkeley, Calif., 1979), 97-145, Springer-Verlag, 1980.

[11] MORSE, M., The existence of polar non-degenerate functions on differentiable manifolds, Ann. of Math. 71(1960), 352-383.

[12] Morse, M., CAIRns, S. S., Critical Point Theory in Global Analysis and Differential Topology, Academic Press, 1969.

[13] Palais, R. S., Terng, Chun-Lian, Critical Point Theory and Submanifold Geometry, Springer-Verlag, 1988.

[14] PAJITNOV, A. V., On the asymptotics of Morse numbers of finite covers of manifolds, math. DG/9810136, October 22, 1998, 13pp

[15] RASSIAS, G. M., On the non-degenerate critical points of differentiable functions, Tamkang J. of Math. 10(1979), 67-73. 